\section{Fretting away at drug targets}

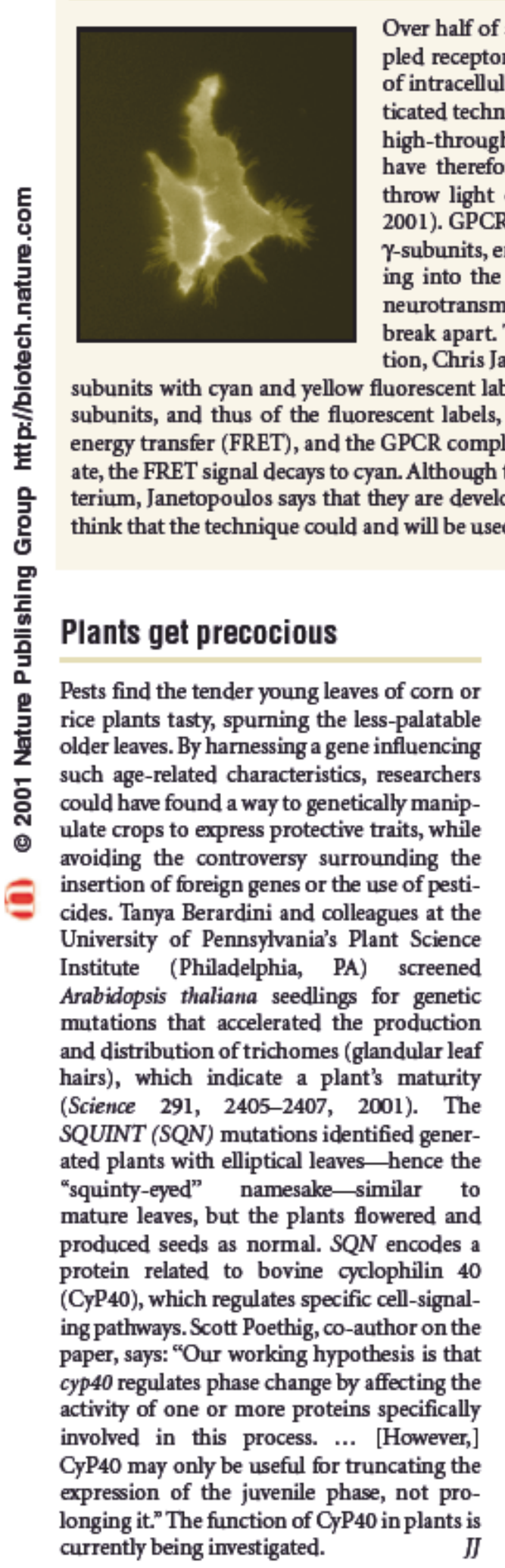

Research briefs were written by Aaron

Bouchie, Liz Fletcher, Judy Jamison, and Christopher Morrison.

\section{Mending a broken heart}

Various types of cell transplant have been tried-albeit with limited success-to repair the damage to the heart inflicted by a heart attack. However, two studies raise hopes that cells from a patient's bone marrow could be used to rescue injured hearts. In one study, researchers at Columbia University (New York) extracted a specific subpopulation of stem cells from human bone marrow-so-called angioblasts-that give rise to the endothelial cells lining blood vessels. When injected into the tails of immune-deficient rats, the angioblasts migrated to the heart, triggering the growth of new blood vessels in both damaged and undamaged myocardium (Nat. Med. 7, 430-436, 2001). There was a $30 \%-40 \%$ inprovement in heart function in rats treated with stem cells. A different tactic was employed in the second study, in which a specific population of multipotent cells was injected directly into ischemic mouse heart (Nature, 410, 701-706, 2001). The cells, which were tracked using a green fluorescent protein label, took up residence in the damaged tissue and created not only new blood vessels but also new cardiac muscle. Moreover, there was a measured improvement in heart function in transplant recipients. Although there are many questions still to answer about the viability of this approach - the least being the practicalities of harvesting stem cells from heart attack patients-the researchers say there is "compelling evidence" that the technique could benefit humans.

\section{Bacterial serial killers}

A novel use has been found for the biotechnologist's ubiquitous laboratory tool - the bacteriophage. Bacteriophages naturally infect and kill bacteria, but researchers have now identified a deadly bacteriophage extract that can kill bacteria on contact (Proc. Natl. Acad. Sci. $98,4107-4112,2001)$. Researchers from the Rockefeller University (New York) extracted the enzyme, lysin, from bacteriophage specific to group A streptococci- the cause of "strep" throat, rheumatic fever, and also ${ }^{\alpha}$ flesh-eating ${ }^{\circ}$ infections. When lysin was given orally and nasally to mice infected with group A streptococci, it eradicated the pathogen by punching holes in its cell walls. The surrounding microflora were largely unaffected. Although further studies are needed to ensure that bioactive bacterial cell wall fragments are not released systemically, bacteriophage enzymes could be a novel means of preventing infections by clearing reservoirs of potentially pathogenic bacteria from human mucous membranes. Because the enzyme kills on contact, it avoids the potential risk of antibiotic resistance. Vincent Fischetti, senior author on the paper, says the team will next engineer a single bacteriophage enzyme to target several pathogenic bacteria.

$A B$

\section{Skin therapy}

In healthy skin, a thin layer of tough keratinized epidermal cells protects the body from dehydration and attack by microorganisms. This protective barrier is built from basal skin cells, which proliferate and migrate upward from the lower (basal) skin layers. Researchers at the University of California at San Diego (CA) School of Medicine have now identified the essential trigger for this process-keratinocyte-differentiating factor, $\mathrm{kDIF}$ (Nature $410,710-714,2001$ ). While studying the role of I-kappa-B kinase (IKK) in inflammation, Michael Karin and colleagues found that a catalytic subunit of the kinase, IKK $\alpha$, regulated keratinocyte proliferation and differentiation. IKK $\alpha$-knockout mice developed basal cell carcinomas, caused by the unchecked proliferation of basal skin cells, but at the time it was unclear why. The researchers suspected that a second factor was involved after grafting skin from IKK $\alpha$-deficient mice onto wild-type controls. Though abnormal at first, IKK $\alpha$ deficient skin soon acquired a normal appearance, indicating that a soluble factor was diffusing from the host skin. The molecular identity of $\mathrm{kDIF}$ is as yet unknown, but its discovery is a potential boon for the treatment of skin cancers and for tissue engineers hoping to create more functional skin grafts. $\quad \mathrm{CM}$ 